\title{
Influence of Variety and Maturity Level on Natural Convective Heat Drying of Four Onion Varieties Grown in Senegal
}

\author{
Ngoné Fall Beye ${ }^{1,2,3^{*}}$, Cheikhou Kane ${ }^{1,2}$, Nicolas Cyrille Ayessou ${ }^{1,2}$, Cheikh Talla4, \\ Abdou Sene', Codou Mar Diop ${ }^{1,2}$ \\ ${ }^{1}$ Laboratoire d'Electrochimie et de Procédés Membranaires (LEPM), ESP-UCAD, Dakar, Sénégal \\ ${ }^{2}$ Centre d'Etudes sur la Sécurité alimentaire et les Molécules fonctionnelles (CESAM-RESCIF), ESP-UCAD, Dakar, Sénégal \\ ${ }^{3}$ Laboratoire des Sciences Biologiques, Agronomiques et de Modélisation des Systèmes Complexes (LaBAM)/UGB, Saint-Louis, \\ Sénégal \\ ${ }^{4}$ Institut Pasteur de Dakar, Unité d'épidémiologie des maladies infectieuses, Dakar, Sénégal \\ Email: ^fallbeye@gmail.com, ngone-fall.beye@ugb.edu.sn
}

How to cite this paper: Beye, N.F., Kane, C., Ayessou, N.C., Talla, C., Sene, A. and Diop, C.M. (2018) Influence of Variety and Maturity Level on Natural Convective Heat Drying of Four Onion Varieties Grown in Senegal. Food and Nutrition Sciences, 9, 997-1013.

https://doi.org/10.4236/fns.2018.98073

Received: July 23, 2018

Accepted: August 18, 2018

Published: August 21, 2018

Copyright $\odot 2018$ by authors and Scientific Research Publishing Inc. This work is licensed under the Creative Commons Attribution International License (CC BY 4.0).

http://creativecommons.org/licenses/by/4.0/

\section{(c) (i) Open Access}

\begin{abstract}
The considerable post-harvest losses (5\% to $40 \%$ depending on storage time) due to the high water content level of the onion varieties in Senegal are the main cause of the problem of access to local onion all year round. Therefore, drying is one of the techniques that can be used to solve the problem of onion perishability. This study deals with the characterization of naturally convective kinetics drying of four onion varieties in relation to their maturity level. The experiment was carried out using the gravimetric method. The Welch and Turkey statistical tests display a significant difference between the effective diffusivity coefficients depending on the maturity level within each variety and across the four varieties. The effective diffusivity coefficients of the Galmi Violet, Safari, Gandiol F1 and Orient F1varieties range from $2.18 \times$ $10^{-11} \pm 2.69 \times 10^{-12}$ to $1.32 \times 10^{-10} \pm 1.17 \times 10^{-11} \mathrm{~m}^{2} \cdot \mathrm{s}^{-1}$ at a maturity level less than $80 \%$. When the maturity level is greater than $85 \%$, the effective diffusivity coefficients range from $1.30 \times 10^{-11} \pm 1.24 \times 10^{-12}$ to $8.05 \times 10^{-11} \pm 8.94 \times$ $10^{-13} \mathrm{~m}^{2} \cdot \mathrm{s}^{-1}$. As far as the activation energy is concerned, the study only reveals a significant difference between the varieties whatever the maturity level is. The Galmi Violet variety stands out with an average activation energy of $66.71 \pm 0.12 \mathrm{KJ} \cdot \mathrm{mol}^{-1} \mathrm{~K}^{-1}$ for the maturity level below $80 \%$ and $58.74 \pm 0.11 \mathrm{KJ} \cdot \mathrm{mol}^{-1}$ for the maturity level above $85 \%$. For the three remaining varieties, the average activation energy ranges from $58.15 \pm 0.19$ to 59.12 $\pm 0.13 \mathrm{KJ} \cdot \mathrm{mol}^{-1}$ for a maturity level less than $80 \%$ whereas the rates go from $47.63 \pm 0.28$ to $49.96 \pm 0.77 \mathrm{KJ} \cdot \mathrm{mol}^{-1}$ when the maturity level is greater than $85 \%$. In summary, the higher the maturity level is, the lower the effective diffusivity coefficients will be. The same tendency was observed with the activa-
\end{abstract}


tion energy. The Galmi Violet variety represents the limitative one in case of the drying of the four varieties mix together.

\section{Keywords}

Allium cepa L., Drying Kinetics, Maturity Level, Effective Diffusivity Coefficient, Activation Energy

\section{Introduction}

Onions, known as Allium cepa L., are the second largest vegetable grown around the world after tomatoes (93.17 versus 177.75 million tons) [1].

With an annual consumption that ranges from 150,000 and 250,000 tons onions represent $25 \%$ of the households expenses in Senegal. Throughout the country, onion bulbs are most commonly used in cooking recipes to enhance meals tastes.

However, due to their high water content level that is between $83 \%$ and $92 \%$ depending on the varieties [2] [3] [4], onions cause considerable conservation challenges to both producers and consumers.

In fact, water is the one main cause of biochemical and microbiological degradation. Thus, its mastery constitutes an important step in food product preservation.

Among the techniques used to master water in food products, drying is the oldest one, but it is also very demanding in terms of energy consumption. Besides, it may alter the nutritional and organoleptic properties of food products. Therefore, water mastery remains necessary for the cost and quality control [5] [6] [7].

Previous research studies on different food products show that drying kinetics depends on the drying conditions, the interactions between the different constituents of the food product particularly water and the texture of the product.

- According to Clemente et al. (2011) on potatoes [8], Doymaz (2010) on bananas [9], Babalis et al. (2004) on figs [5] as well as Krokida et al. (2003) on different products (celery, onion, garlic, tomato, corn, etc.) [4], the drying time decreases when the drying temperature is higher (temperature comprised between $30^{\circ} \mathrm{C}$ and $85^{\circ} \mathrm{C}$ ). Moreover, the effective diffusivity coefficient increases with the temperature (Doymaz, 2010) [9].

- According to Clemente et al. (2011) on potatoes [8] as well as Babalis et al. (2004) on figs [5], the effective diffusivity coefficient no longer increases when the drying air velocity exceeds $2 \mathrm{~m} \cdot \mathrm{s}^{-1}$.

- For Brooks et al. (2004) on tomatoes [10], Madamba et al. (1996) on garlic (2 to $4 \mathrm{~mm}$ thick) [11], the drying time decreases when the thickness decreases while the drying rate increases, allowing thus to preserve the quality of food product.

As far as onions are concerned, Krokida et al. (2003) [4], Sarsavadia et al. (1999) 
[12], and Kiranoudis et al. (1992) [13] have shown that, with drying air velocity comprised between 0.25 and $1.5 \mathrm{~m} \cdot \mathrm{s}^{-1}$, the drying rate increases whereas drying air velocity higher than $1.5 \mathrm{~m} \cdot \mathrm{s}^{-1}$ do not have any more impact on the drying rate. The smaller the thickness of the samples is, the higher the drying rate will be (Sarsavadia et al., 1999; Kiranoudis et al., 1992) [12] [13].

The influence of the thickness on the drying rate of onions matches the Mazza and Lemaguer's (1980) [14] results (1.5 mm thickness). However, the characteristics of the drying kinetics of onions reported by these different studies display differences related to the experimental conditions and the origin of the samples.

Nonetheless, no characterization of the drying kinetics of the Senegalese onion varieties was found in the literature. As a matter of fact, the food industries, which are the main users of dried onions in Senegal, are compelled to import it given the non-mastery of the drying procedures whereas about $20 \%$ to $30 \%$ of post-harvest losses are noticed each production period.

These shortcomings justify the current study which objective is to characterize the drying kinetics of four onion varieties grown up in Senegal within the temperature interval ranging from $50^{\circ} \mathrm{C}$ to $70^{\circ} \mathrm{C}$ in order to determine the effective diffusivity coefficients as well as the required activation energy.

\section{Materials and Methods}

\subsection{Materials}

\subsubsection{Vegetal Material}

The vegetal material used in this study is local onions picked up from the RAO cooperative in Saint Louis. The study focuses on the main four onion varieties grown in Senegal, namely the Galmi Violet, the Safari, the Gandiol F1, and the Orient F1.

Two maturity levels were tested for each of the four varieties. At the harvest period, the maturity levels expressed in terms of onion leaves loss percentage are:

- Less than $80 \%$ for the varieties harvested in March 2015 and 2016.

- Greater than 85\% for the varieties harvested in June 2016 and 2017.

For the March period, the harvests were performed without regard for the technical itinerary, that is to say, before the full maturity of the bulbs whereas those of June were well-timed [15] [16]. These two maturity level can be observed in both March and June harvest period depending on the farmers practices and have a great impact on post-harvest storage.

\subsubsection{Drying and Analysis Materials}

The experimental instruments include the following items:

- An oven with a precision of $0.1^{\circ} \mathrm{C}$.

- A thermohygrometer with a precision of $1^{\circ} \mathrm{C}$ and $3.5 \%$.

- A precision scale (reliability rate of $0.0001 \mathrm{~g}$ ).

- A Micrometer (0 - $25 \mathrm{~mm}$ ) with a precision of $0.001 \mathrm{~mm}$.

- Pyrex capsules and laboratory glassware. 


\subsubsection{Statistical Analysis and Graphical Tools}

The following softwares were used for data analysis.

- The R software version 3.4.0 (Team R Core, 2017) was used for analyzing variance and measure concordances.

- The 2016 version of the Excel spreadsheet program was used as a scientific calculations tool for graphic representations and the specification of the effective diffusivity coefficients and the activation energy.

\subsection{Methods}

\subsubsection{Experimental Protocol}

The characterization of the drying kinetics of the local onion varieties was carried out through the gravimetric method. The drying was performed in an oven with temperatures ranging from $50^{\circ} \mathrm{C}$ to $70^{\circ} \mathrm{C}$ with a $5^{\circ} \mathrm{C}$ step.

The drying air velocity was set at $2.4 \mathrm{~m} \cdot \mathrm{s}^{-1}$ and the relative humidity in the oven ranged from $10 \%$ to $15 \%$.

The experiments were carried out in triple with a sample of ten grams of thinly chopped onions from three different bulbs spread in monolayer in the pyrex cup.

The experiments were carried out for two consecutive years in March 2015 and 2016 for the maturity level less than $80 \%$ and in June 2016 and 2017 for the maturity level greater than $85 \%$.

The initial moisture level $\left(X_{0}\right)$ and the moistureat the end of each drying hour $\left(X_{\text {exp, }}\right)$ were determined via desiccation at $105^{\circ} \mathrm{C}$ for two hours:

- The initial moisture level

$$
X_{0}=\frac{m_{0}-m_{s, 0}}{m_{s, 0}}
$$

with $m_{0}$ the weight of the non-dried product and $m_{s, 0}$ its weight after desiccation.

- The moisture level at the different drying hours

$$
X_{\text {exp }, t}=\frac{m_{t}-m_{s, t}}{m_{s, t}}
$$

with $m_{t}$ the weight of the product at the end of a given time and $m_{s, t}$ its weight after desiccation.

\subsubsection{Drying Kinetics}

The drying kinetics of the four varieties is characterized by drying curves of the reduced moisture level in relation to time:

$$
X_{r \exp , t}=f(t)
$$

The experimental reduced moisture level at the different drying periods is calculated via the following formulae

$$
X_{r e x p, t}=\frac{X_{e x p, t}-X_{e q}}{X_{0}-X_{e q}}
$$

With $X_{e q}$ : The equilibrium moisture content, negligible compared to $X_{e x p, t}$ and $X_{0}$ for long drying periods. 
- $\quad X_{\text {rexp, } i}$ Reduced moisture level at the different drying times.

- $\quad X_{\text {exp, } i}$ Moisture level at the different drying times.

- $X_{0}$ : Initial moisture level.

\subsubsection{Determination of the Effective Diffusivity Coefficients}

Effective diffusivity coefficients at the different temperatures were calculated by applying Fick's second law to the evolution of the reduced water content in the second phase at a constant speed (Figure 1 and Figure 2).

$$
D_{\text {eff }} \frac{\partial^{2} X}{\partial x^{2}}=\frac{\partial X}{\partial t}
$$

The solution of Fick's second law in a linear and stationary $x$ space is as follows:

$$
\operatorname{Ln} X_{r \text { exp.t }}=-\left(\frac{\beta^{2} D_{e f f}}{e^{2}}\right) t+\operatorname{Ln} \frac{4}{\beta^{2}}
$$

- $D_{\text {effi }}$ Diffusion coefficient in $\mathrm{m}^{2} \cdot \mathrm{s}^{-1}$;

- $\beta$ : Mass transfer coefficient in $\mathrm{m} \cdot \mathrm{s}^{-1}$;

- and (e) the thickness of the onion pieces measured with a digital micrometer (Table 1).

Given that the thickness of the samples was very thin, the deformation of the product during the drying process is negligible.

\subsubsection{Determination of the Activation Energy}

The diffusion responsible for water movement on the decreasing speed part (phase 2) of the drying speed curves obey the Arrhénius' law. The different effective diffusivity coefficients of the different onion varieties determined from the Equations (1), (2), and (3) permit to calculate the amount of activation energy necessary for the mechanism to operate, by drawing the curves according to the following equation.

$$
\operatorname{Ln} D_{e f f}=\operatorname{Ln} D_{0}-\frac{E_{a}}{R} \frac{1}{T}
$$

with $D_{0}$ : the Arrhenius parameter, $E_{a}$ : the activation energy in $\mathrm{J} \cdot \mathrm{mol}^{-1}, R$ : the constancy of perfect gases $\left(8.31 \mathrm{~J} \cdot \mathrm{mol}^{-1} \mathrm{~K}^{-1}\right)$ and $T$ : Kelvin-based temperature.

Table 1. Thickness of the different onion varieties samples.

\begin{tabular}{ccccccccc}
\hline & \multicolumn{8}{c}{ Varieties } \\
\cline { 2 - 9 } & \multicolumn{9}{c}{ Galmi Violet } & \multicolumn{2}{c}{ Safari } & \multicolumn{3}{c}{ Gandiol F1 } & Orient F1 \\
\cline { 2 - 9 } Layer $\left(\times 10^{-3} \mathrm{~m}\right)$ \\
\hline $\mathbf{T}\left({ }^{\circ} \mathrm{C}\right)$ & March & June & March & June & March & June & March & June \\
\hline $\mathbf{5 0}$ & 1.48 & 1.27 & 1.51 & 1.19 & 1.51 & 1.26 & 1.36 & 1.06 \\
$\mathbf{5 5}$ & 1.78 & 1.49 & 1.76 & 1.43 & 2.02 & 1.58 & 1.75 & 1.34 \\
$\mathbf{6 0}$ & 1.98 & 1.69 & 1.82 & 1.67 & 2.09 & 1.50 & 1.77 & 1.33 \\
$\mathbf{6 5}$ & 2.03 & 1.84 & 2.00 & 1.92 & 2.11 & 1.63 & 1.88 & 1.36 \\
$\mathbf{7 0}$ & 2.06 & 1.64 & 2.33 & 1.95 & 2.14 & 1.60 & 2.05 & 1.44 \\
\hline
\end{tabular}




\section{Results}

Drying kinetics is characterized by a follow-up of the moisture level during the drying time from the Equations (1), (2), and (3). In theory, these curves represent three phases for non-hygroscopic and barely deformable products. These three phases are the period of temperature setting, the decreasing period (isenthalpic stage, i.e., the temperature of the product remains constant and identical to that of the surrounding open air), and the constant period.

The effective diffusivity coefficients at the different drying temperatures are calculated from the drawing of the curves Ln Xrexp, tin relation to the drying times (Equations (4) and (5)) on the isenthalpic stage.

Concerning the activation energy, it is determined by the evolution of the effective diffusivity coefficients in relation to the reverse drying temperature from Equation (6).

\subsection{Drying Kinetics}

The characteristic curves of drying presented in Figure 1 and Figure 2 were drawn from the weight loss during the drying time of the onion varieties at the different maturity levels.
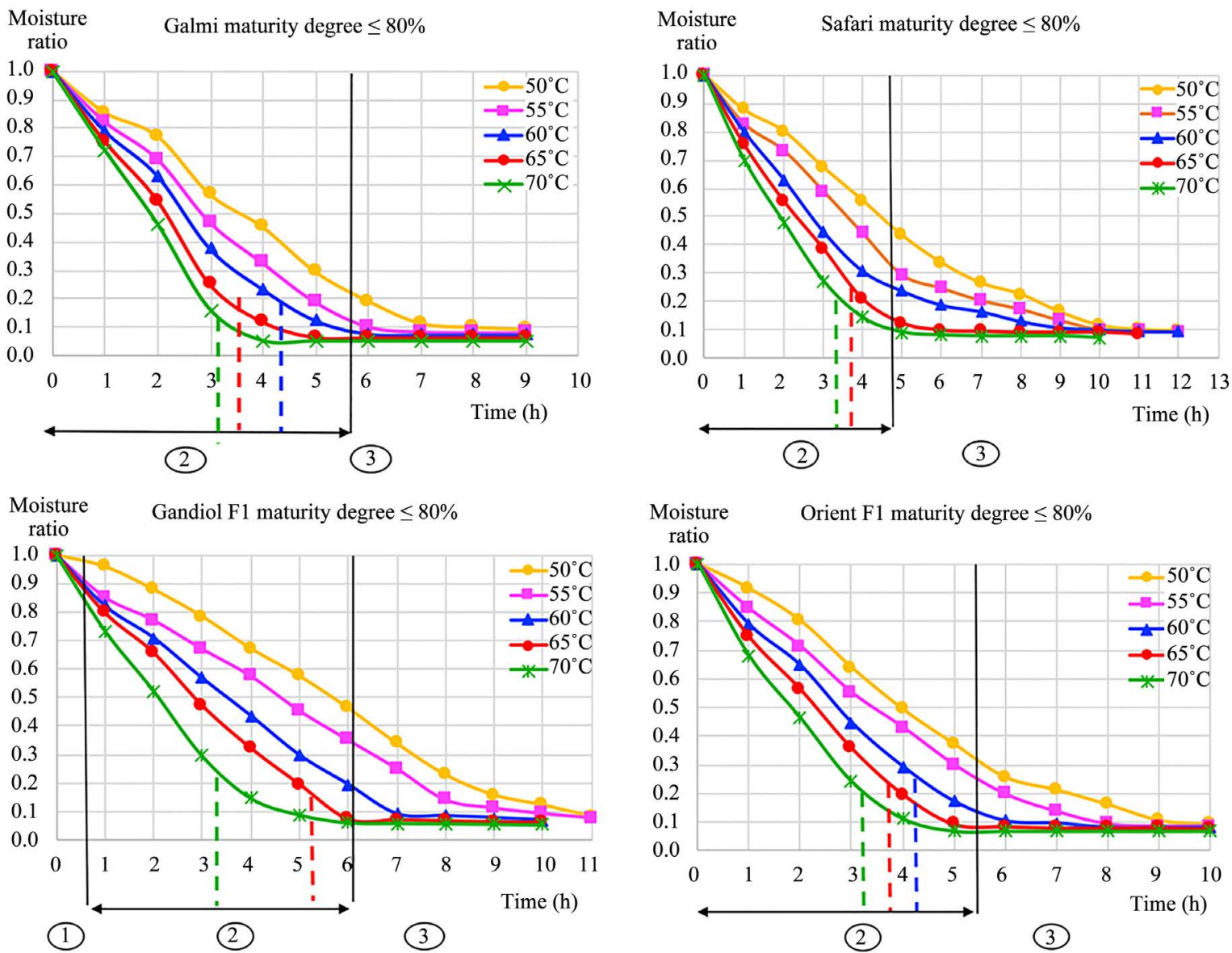

Figure 1. Evolution according to drying time of the reduced moisture level of the onion varieties harvested at a maturity level less than 80\% (average of March 2015 and 2016 experimental results). 

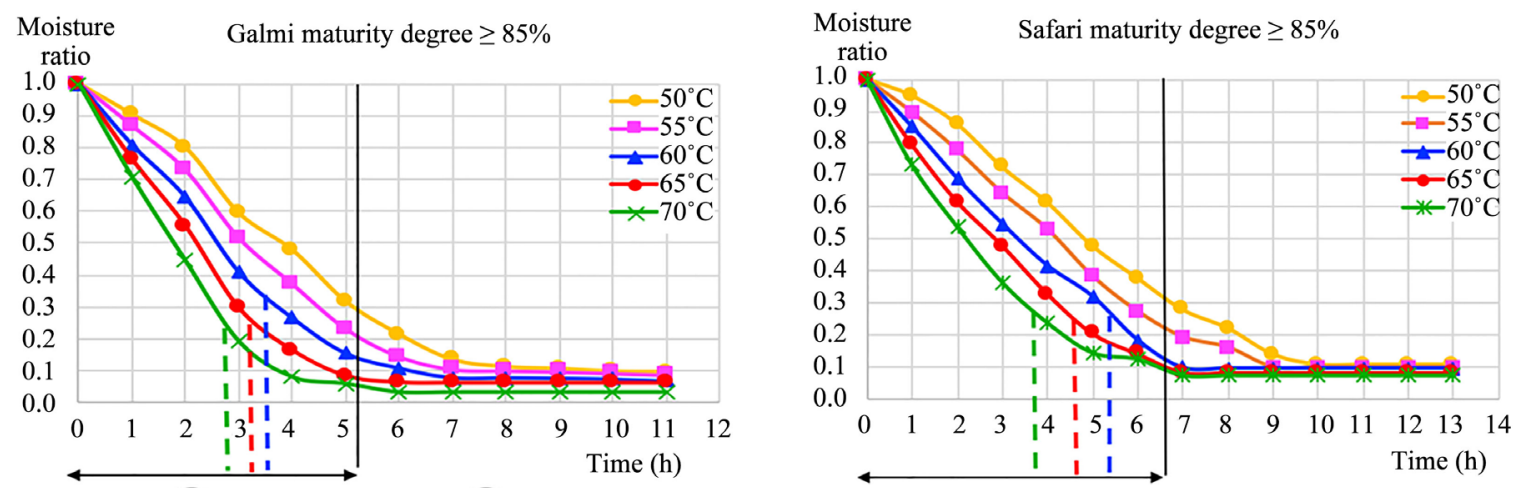

(2)

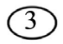

(2)
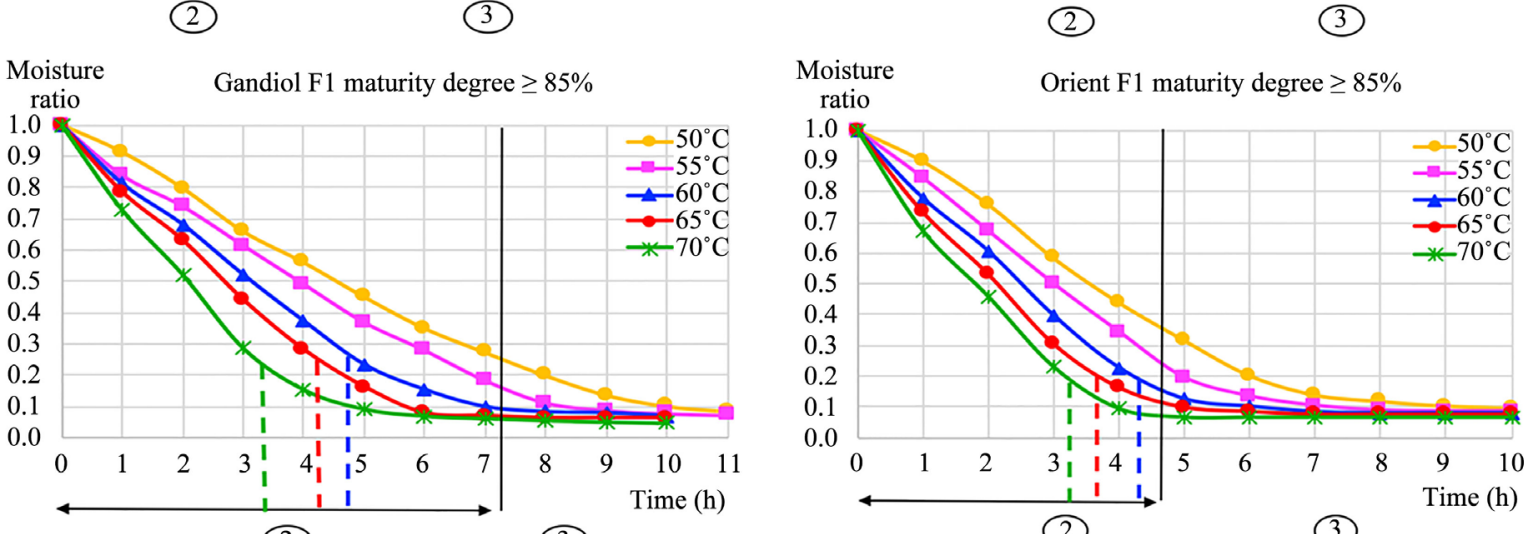

(2)

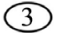

(2)

(3)

Figure 2. Evolution according to drying time of the reduced moisture level of the onion varieties harvested at a maturity level superior or equal to 85\% (average of June 2016 and 2017 experimental results).

\subsubsection{Evolution of Reduced Water Content of the Varieties Harvested in March}

The average reduced moisture level (Figure 1) obtained from the experimental results of March 2015 and 2016 shows that the number and duration of the phases changed according to the drying temperature of the four varieties.

The temperature-setting phase does not appear on the drying characteristic curves of the Galmi Violet, Safari, and Orient F1 varieties, whatever the drying temperature. The temperature-setting phase only exists for the Gandiol F1 variety at the drying temperature of $50^{\circ} \mathrm{C}$ with phase duration inferior to one hour.

Besides, the higher the drying temperature is, the more the duration of phase 2 decreases. The reverse is noticed with phase 3 . Every $5^{\circ} \mathrm{C}$ step temperature increase induces a 30 minute to two hour decrease. The duration of phase 2 goes from four hours four-five minutes to six hours across varieties.

\subsubsection{Evolution of Reduced Water Content of the Varieties Harvested in June}

Figure 2 displays the evolution of the reduced moisture level average of the varieties harvested at a maturity level greater than $85 \%$. This average was calculated from the recorded weight losses of the experiments carried out in June 2016 and 2017.

The characteristic curves of the four varieties (Figure 2) show the existence of two phases namely the isenthalpic phase and the constant phase whatever the 
drying temperature. The duration of phase 2 ranges from five to seven hours depending on the varieties, and it decreases from 30 minutes to one hour for every $5^{\circ} \mathrm{C}$ step increase of the temperature. The reverse effect was observed for phase 3.

By comparing the evolution of the reduced moisture level average in relation to the maturity level of the varieties (Figure 1 and Figure 2), it appears that:

- the more advanced the maturity level is, the longer the duration of phase 2 is;

- the effect of the temperature raise on the variability of the duration of phase 2 is more visible when the maturity level is $\leq 80 \%$ rather than $\geq 85 \%$.

\subsection{Determination of the Effective Diffusivity Coefficients}

Figure 3 and Figure 4 respectively display the evolution of the Napierian logarithm

of the average reduced moisture level in relation to the drying time for a maturity

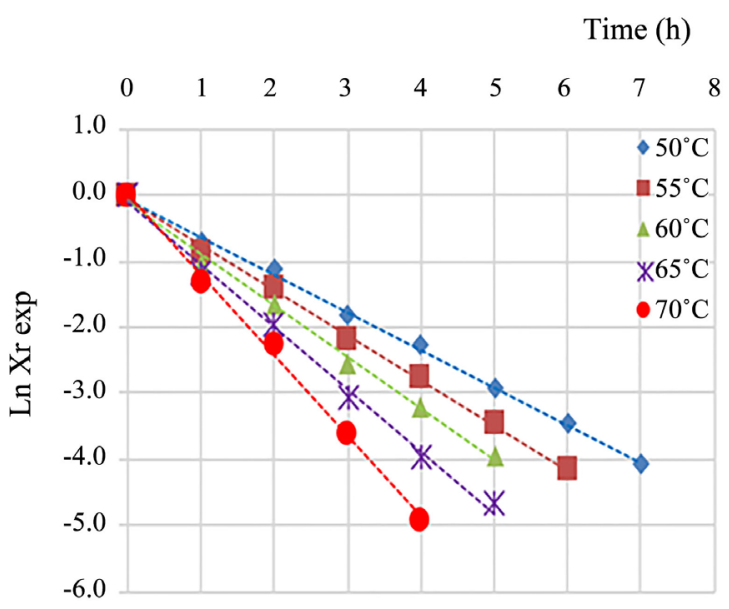

Galmi maturity degree $\leq 80 \%$

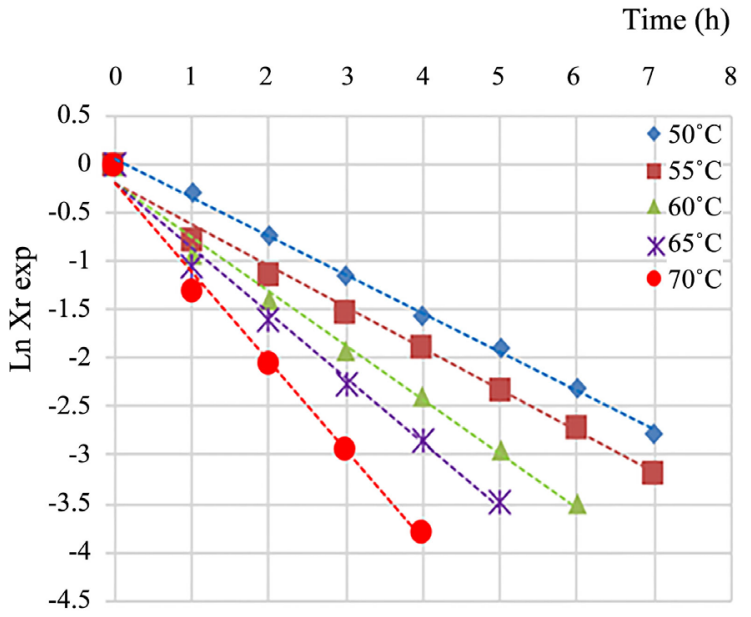

Gandiol F1 maturity degree $\leq 80 \%$

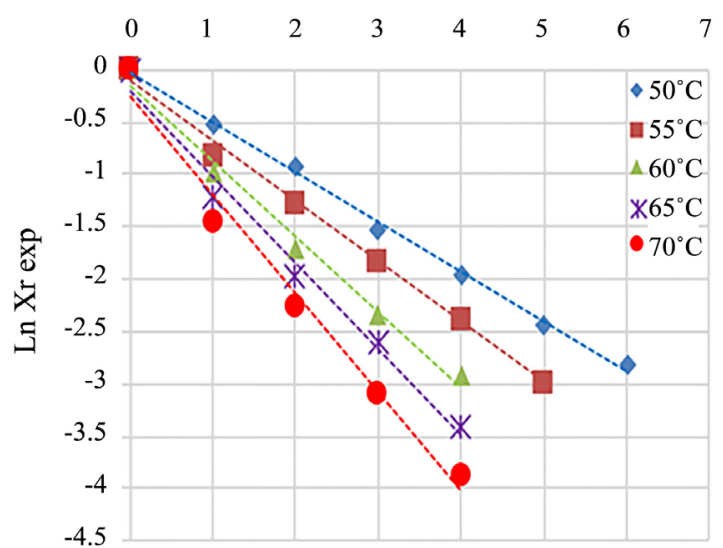

Safari maturity degree $\leq 80 \%$

Time (h)

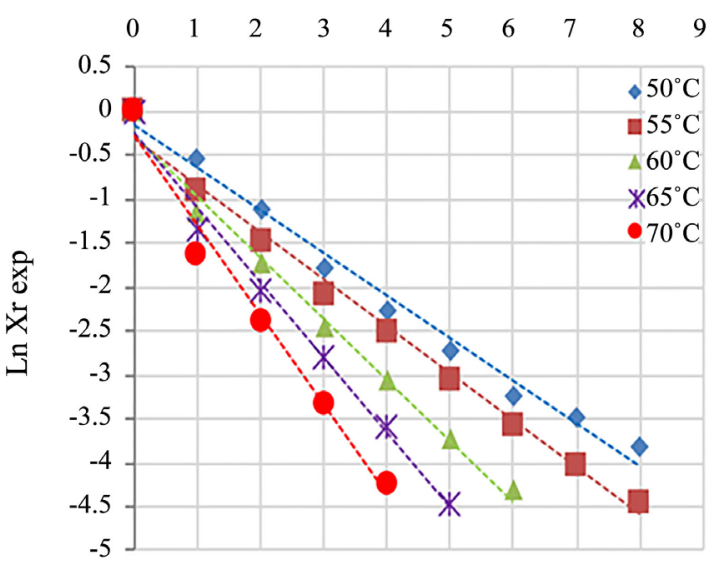

Orient $\mathrm{F} 1$ maturity degree $\leq 80 \%$

Figure 3. Evolution in relation to the time of the moisture level Napierian logarithm (in the drying isenthalpic phase of the varieties at a maturity level $\leq 80 \%)$. 


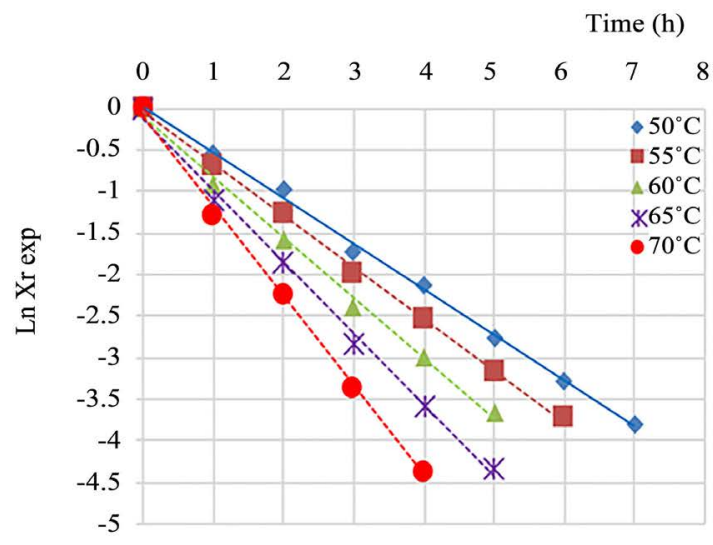

Galmi maturity degree $\geq 85 \%$

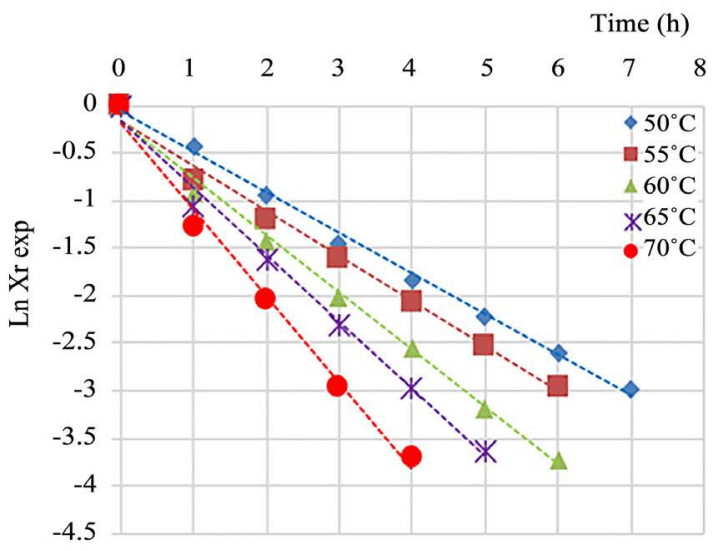

Gandiol F1 maturity degree $\geq 85 \%$

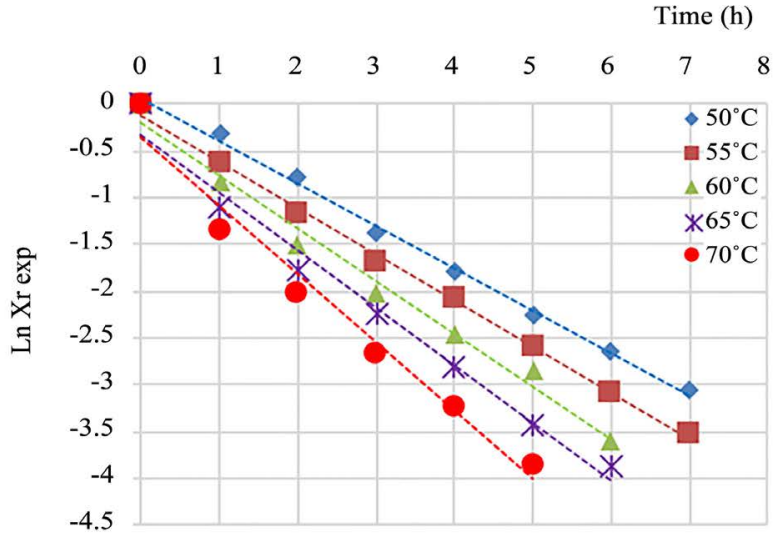

Safari maturity degree $\geq 85 \%$

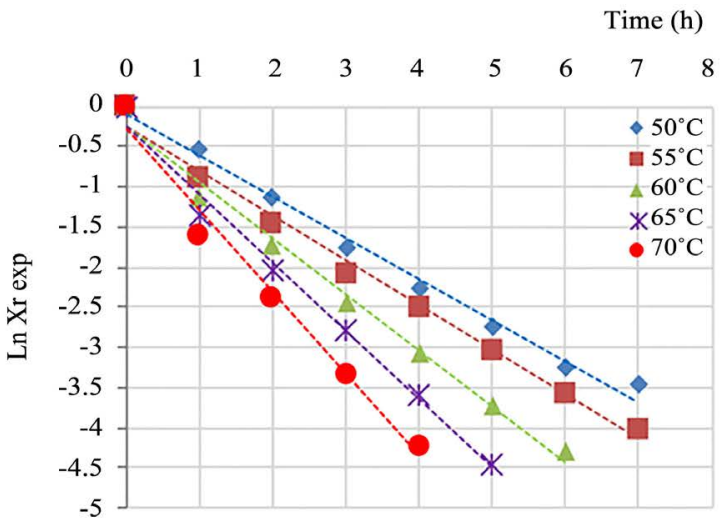

Orient F1 maturity degree $\geq 85 \%$

Figure 4. Evolution in relation to the time of the moisture level Napierian logarithm (in the drying isenthalpic phase of the varieties at a maturity level $\geq 85 \%$ ).

level of the varieties below $80 \%$ and above $85 \%$. The values for the reduced moisture level average taken into account are those of phase 2 (Figure 1 and Figure 2) where the diffusivity mechanism commands the drying kinetics.

The slopes of the curves for the Galmi Violet and Safari varieties at a maturity level less than $80 \%$ are superior to those at a maturity level greater than $85 \%$. The reverse situation is noticed for the Gandiol F1 variety, whereas for the Orient F1 variety, the slopes of the curves are identical. The values of the slopes and intercepts respectively range from 0.40 to 1.22 , and from 0.035 to 0.62 . Those values along with the thickness of the samples (Table 1) integrated in Equation (5) allowed to determine the effective diffusivity coefficients averages (Table 2).

Globally, the effective diffusivity coefficient averages increase with the temperature for all the four varieties. For each $5^{\circ} \mathrm{C}$ step temperature raise, the multiplying factors of the effective diffusivity coefficients averages at the maturity levels less than $80 \%$ and greater than $85 \%$ are respectively specified below:

- Galmi Violet from 1.35 to 1.69 and from 1.28 to 1.48 ;

- Safari from 1.30 to 1.53 and from 1.16 to 1.39 ; 
Table 2. Effective diffusivity coefficients averages depending on the maturity level and the drying temperature of the Galmi Violet, Safari, Gandiol F1 and Orient F1 varieties.

\begin{tabular}{ccccccc}
\hline & & \multicolumn{5}{c}{ Effective diffusivity coefficient Deff $\left(\times 10^{-11} \mathrm{~m}^{2} \mathrm{~s}^{-1}\right)$} \\
\cline { 3 - 7 } & & \multicolumn{5}{c}{ Temperature $\left({ }^{\circ} \mathrm{C}\right)$} \\
\hline \multirow{2}{*}{ Varieties } & Crop period & $\mathbf{5 0}$ & $\mathbf{5 5}$ & $\mathbf{6 0}$ & $\mathbf{6 5}$ & $\mathbf{7 0}$ \\
& March & 2.97 & 5.01 & 6.77 & 9.54 & $1.32^{(\mathrm{a})}$ \\
\multirow{2}{*}{ Safari } & June & 2.25 & 3.32 & 4.63 & 6.29 & 8.05 \\
& March & 2.60 & 3.98 & 5.17 & 6.77 & 9.77 \\
\multirow{2}{*}{ Gandiol F1 } & June & 1.67 & 2.28 & 3.16 & 4.14 & 4.81 \\
& March & 2.42 & 3.58 & 4.98 & 6.16 & 8.92 \\
& June & 1.68 & 2.50 & 2.87 & 3.96 & 4.86 \\
Orient F1 & March & 2.18 & 3.30 & 4.18 & 5.88 & 8.12 \\
& June & 1.30 & 1.92 & 2.35 & 3.07 & 3.98 \\
\hline
\end{tabular}

Caption: ${ }^{(a)}: \times 10^{-10}$. March (maturity level $\leq 80 \%$ ); June (maturity level $\geq 85 \%$ ).

- Gandiol F1 from 1.24 to 1.48 and 1.15 to 1.48 ;

- Orient F1 from 1.26 to 1.52 and from 1.23 to 1.47 .

From one maturity level to another within the same variety, the effective diffusivity coefficients averages at the maturity level below $80 \%$ are higher than those at the maturity level above $85 \%$ whatever the temperature. The multiplying factors range from 1.32 to 2.04 .

From one variety to another, the effective diffusivity coefficients averages of the Galmi Violet variety (ranging from $2.25 \times 10^{-11}$ to $1.32 \times 10^{-10} \mathrm{~m}^{2} \cdot \mathrm{s}^{-1}$ ) are superior to those of the three other varieties (ranging from $1.30 \times 10^{-11}$ to $9.77 \times$ $10^{-11} \mathrm{~m}^{2} \cdot \mathrm{s}^{-1}$ ) whatever the maturity level. The multiplying factors vary from 0.91 to 2.05 .

\subsection{Determination of the Activation Energy in Relation to Harvest Periods}

The Napierian logarithm curves of the effective diffusivity coefficients averages per period are presented in Figure 5. They are represented on the reverse temperature, thus allowing the calculation of the activation energy.

The tendency curves obtained via regression for the four varieties over the harvest periods of March and June are line the equations of which are described in Table 3. All of the correlation coefficients range from 0.984 to 0.996 .

The activation energy per period (Table 4) ranges from 60.25 to $47.63 \mathrm{KJ} \cdot \mathrm{mol}^{-1}$. It is calculated from the slopes of the different equations set by linear regression (Table 3).

Whatever the maturity level, the activation energy for the Galmi Violet variety (Table 4) is superior to that of the three other varieties (multiplying factors ranging from 1.13 et 1.23 ). The difference is $9.59 \pm 1.32 \mathrm{KJ} \cdot \mathrm{mol}^{-1}$ for the maturity level below $80 \%$ and $8.07 \pm 0.49 \mathrm{KJ} \cdot \mathrm{mol}^{-1}$ for the maturity level above $85 \%$. The activation energy of the three other varieties is almost identical, with in a 

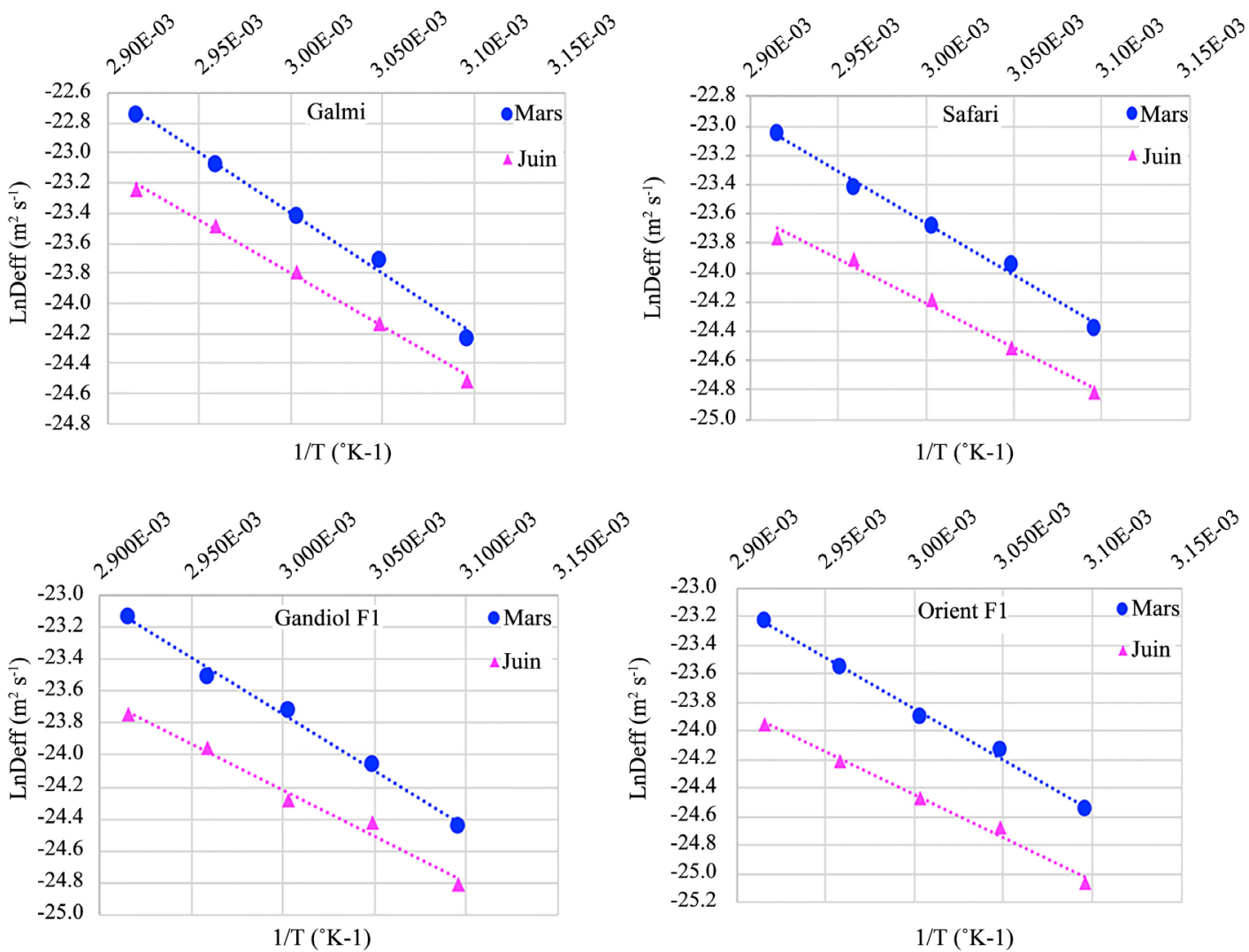

Figure 5. Evolution of the effective diffusivity coefficients average of the four varieties in relation to the different drying temperatures.

Table 3. Equation of the effective diffusivity coefficients averages and correlation coefficients given the harvest period.

\begin{tabular}{cccc}
\hline Varieties & Crop period & Equation & Correlation coefficients \\
\hline \multirow{2}{*}{ Galmi Violet } & March & Ln $D_{\text {eff }}=-8027.4(1 / \mathrm{T})+0.68$ & 0.991 \\
& June & Ln $D_{\text {eff }}=-7068.9(1 / \mathrm{T})-2.60$ & 0.996 \\
\multirow{2}{*}{ Safari } & March & Ln $D_{\text {eff }}=-7059.0(1 / \mathrm{T})-2.49$ & 0.993 \\
& June & $\operatorname{Ln} D_{\text {eff }}=-6011.9(1 / \mathrm{T})-6.17$ & 0.988 \\
\multirow{2}{*}{ Gandiol F1 } & March & $\operatorname{Ln} D_{\text {eff }}=-6997.0(1 / \mathrm{T})-2.75$ & 0.993 \\
& June & $\operatorname{Ln} D_{\text {eff }}=-5731.5(1 / \mathrm{T})-7.02$ & 0.984 \\
\multirow{2}{*}{ Orient F1 } & March & $\operatorname{Ln} D_{\text {eff }}=-7114.5(1 / \mathrm{T})-2.50$ & 0.995 \\
& June & $\operatorname{Ln} D_{\text {eff }}=-6001.3(1 / \mathrm{T})-6.44$ & 0.992 \\
\hline
\end{tabular}

Table 4. The average activation energy given the harvest period.

\begin{tabular}{ccccc}
\hline & \multicolumn{4}{c}{ Average Activation Energy $\left(\mathrm{KJ} \cdot \mathrm{mol}^{-1}\right)$} \\
\cline { 2 - 5 } & Galmi Violet & Safari & Gandiol F1 & Orient F1 \\
Crop period & Garies & & \\
March & $66.71 \pm 0.12$ & $58.66 \pm 0.15$ & $58.15 \pm 0.19$ & $59.12 \pm 0.13$ \\
June & $58.74 \pm 0.11$ & $49.96 \pm 0.77$ & $47.63 \pm 0.28$ & $49.87 \pm 0.41$ \\
\hline
\end{tabular}


decreasing order, the Orient F1, Safari and Gandiol F1 varieties.

Within each variety, the required activation energy for the maturity level less than $80 \%$ is above that of the maturity level greater than $85 \%$ (multiplying factor ranging from 1.14 to 1.22). The differences for the Galmi Violet, Safari, Gandiol $\mathrm{F} 1$ and Orient F1 varieties are respectively $7.97,8.70,10.52$ and $9.25 \mathrm{KJ} \cdot \mathrm{mol}^{-1}$.

\subsection{Statistical Tests on the Effective Diffusivity Coefficients and Activation Energies}

The results of the statistical tests (variance analysis) show that the temperature, the variety and the maturity level have a very significant influence on the effective diffusivity coefficients with p-values inferior to $2.20 \times 10^{-16}$ (for the temperature and the maturity level) and equal to $1.08 \times 10^{-12}$ (for the variety). Concerning the activation energy, the influence of the period is averagely significant ( $p$-value equals 0.003 ) whereas the influence of the variety is slightly significant (p-value equals 0.05).

\subsubsection{Comparison of Periods within Each Onion Variety}

The Welch Two Sample T-Test was used to compare the averages of the effective diffusivity coefficients and the activation energy within each variety for the March and June periods (Table 5). The tests reveal p-values superior to 5\% except for the effective diffusivity coefficients of the Safari, Gandiol F1, and Orient F1 varieties.

\subsubsection{Comparison of the Varieties according to the Periods}

The analysis of the variance on the effective diffusivity coefficients of the March and June periods respectively resulted in p-values of 0.16 and 0.01 , whereas the p-values for the activation energy are respectively 0.49 and 0.12 . The relation between the different varieties evaluated via the Turkey test is displayed in Table 6.

All the p-values are superior to 5\%. except for the comparison of the effective diffusivity coefficients of the Galmi Violet and Orient F1 varieties over the period of June.

\section{Discussion}

The average effective diffusivity coefficients $\left(\mathrm{m}^{2} \cdot \mathrm{s}^{-1}\right)$ for the March and June periods, which were obtained from the kinetics (Figures 1-4) are respectively within the range below for each onion variety:

- Galmi Violet: $2.97 \times 10^{-11} \pm 5.50 \times 10^{-13}$ and $1.32 \times 10^{-10} \pm 1.17 \times 10^{-11} / 2.25 \times$ $10^{-11} \pm 2.28 \times 10^{-12}$ and $8.05 \times 10^{-11} \pm 8.94 \times 10^{-13}$;

- Safari: $2.60 \times 10^{-11} \pm 2.74 \times 10^{-12}$ and $9.77 \times 10^{-11} \pm 1.50 \times 10^{-13} / 1.67 \times 10^{-11} \pm$ $1.83 \times 10^{-12}$ and $4.81 \times 10^{-11} \pm 4.71 \times 10^{-12}$;

- Gandiol F1: $2.42 \times 10^{-11} \pm 4.07 \times 10^{-13}$ and $8.92 \times 10^{-11} \pm 2.97 \times 10^{-12} / 1.68 \times$ $10^{-11} \pm 5.94 \times 10^{-12}$ and $4.86 \times 10^{-11} \pm 1.44 \times 10^{-11}$

- Orient F1: $2.18 \times 10^{-11} \pm 2.69 \times 10^{-12}$ and $8.12 \times 10^{-11} \pm 2.06 \times 10^{-12} / 1.30 \times$ $10^{-11} \pm 1.24 \times 10^{-13}$ and $3.98 \times 10^{-11} \pm 2.79 \times 10^{-12}$. 
Table 5. Comparison test parameters for the effective diffusivity coefficients and activity energy averages with each variety (March versus June).

\begin{tabular}{ccc}
\hline Varieties & p-value (effective diffusivity) & p-value (activation energy) \\
\hline Galmi Violet & 0.08 & 0.40 \\
Safari & 0.02 & 0.26 \\
Gandiol F1 & 0.03 & 0.18 \\
Orient F1 & 0.01 & 0.09 \\
\hline
\end{tabular}

Table 6. Turkey test parameter for the comparison of effective diffusivity coefficients averages of the different periods across the varieties.

\begin{tabular}{ccccc}
\hline & \multicolumn{4}{c}{ p-value } \\
\cline { 2 - 5 } & \multicolumn{2}{c}{ Effective diffusivity } & \multicolumn{2}{c}{ Activation energy } \\
\hline Compared varieties & March & June & March & June \\
\hline Gandiol F1-Orient F1 & 0.98 & 0.77 & 0.99 & 0.97 \\
Safari-Orient F1 & 0.98 & 1.00 & 1.00 & 0.97 \\
Galmi Violet-Orient F1 & 0.88 & 0.74 & 1.00 & 1.00 \\
Safari-Gandiol F1 & 0.14 & 0.01 & 0.62 & 0.19 \\
Galmi Violet-Gandiol F1 & 0.28 & 0.07 & 0.51 & 0.12 \\
Galmi Violet-Safari & 0.47 & 0.08 & 0.57 & 0.19 \\
\hline
\end{tabular}

These coefficients significantly increase depending on the temperature and the maturity level of the four varieties. The results obtained for the effective diffusivity coefficients are similar to those found in previous studies on fruit and vegetables such as corn, okra, green peas and bananas [9] [17] [18] [19] [20] [21].

The Welch Two Sample T-Test used for the comparison of the effective diffusivity coefficients averages within each variety reveals some significant difference between the periods of March and June with a p-value inferior to $5 \%$ for the Safari, Gandiol F1, and Orient F1 varieties, whereas the Galmi Violet, with a p-value of 0.08 , does not present any significant difference (Table 5). The comparison also indicated that the effective diffusivity coefficients of the March period (maturity level $\leq 80 \%$ ) are superior to those of the June period (maturity level $\geq 85 \%$ ). In short, the higher the maturity level is, the less important the water content inside the matter is, and the lower the effective diffusivity coefficient is [22] [23] [24].

The analysis of the variance across varieties points out some significant difference between the effective diffusivity coefficients only for the June period with a p-value equal to 0.01 . Nonetheless, the Turkey test (Table 6) shows some significant difference between the Galmi Violet and Orient F1 varieties (p-value equal to 0.01 ). Compared to the Safari, Gandiol F1, and Orient F1 varieties, the Galmi Violet shows much more differences ( $\mathrm{p}$-values ranging from 0.01 to 0.47 ) than the three other varieties matched among themselves ( $p$-values ranging from 
0.74 to 1$)$.

Regarding the activation energy (Table 4), the results for the March period (a lower degree of maturity compared to the June period) are more significant than those obtained in June. In fact, inside the decrease phase where the diffusive phenomenon predominates, the higher the free water content is, the more important the activation energy is. Whatever the period, the Galmi Violet variety requires an activation energy (ranging from $58.74 \pm 0.11$ to $66.71 \pm 0.12 \mathrm{KJ} \cdot \mathrm{mol}^{-1}$ ) superior to those of that of the Safari, Gandiol F1, and Orient 1 varieties (ranging from $47.63 \pm 0.28$ to $59.12 \pm 0.13 \mathrm{KJ} \cdot \mathrm{mol}^{-1}$ ). These values match the results found in the literature for a certain number of food products such as okra, green beans, olive leaves [18] [21] [25].

Within each variety as well as across varieties, the statistical analyses on the activation energy show that the p-values are above 5\%. These results mean the absence of significant difference. Nonetheless, the Galmi Violet variety distinguishes itself from the others in that it has p-values ranging from 0.12 to 0.62 .

Therefore, the higher the maturity level of the onion is, the more boundto the other elements the water inside the onion is, the smaller the effective diffusivity coefficient is, and the lower the activation energy is [11] [25] [26] [27] [28]. The mobility and the moisture content in the food depend strongly on their structure which changes according to their maturity level and influences the drying process. Our results are in the range of those obtained for a number of food products both for the effective diffusivity coefficient $\left(10^{-12}\right.$ and $\left.10^{-7} \mathrm{~m}^{2} \cdot \mathrm{s}^{-1}\right)$ and for the activation energy $\left(27.97\right.$ and $\left.83.6 \mathrm{KJ} \cdot \mathrm{mol}^{-1}\right)$ in previous studies.

\section{Conclusions}

The effective diffusivity coefficients of the varieties harvested in March along with the activation energy are higher than those of June. The reasons for these differences are the respect for the technical itinerary during the harvest of the month of June (with a leaf-fall rate superior to $85 \%$ ).

The evolution of the effective diffusivity coefficients averages regarding the temperature reveals some significant difference within each variety for the $80 \%$ maturity level as well as that of $85 \%$. Nonetheless, for any given temperature, the study of the maturity level effect appears a significant difference only for the Safari, Gandiol F1, and Orient F1 varieties. A comparison across varieties shows some significant difference only between the Galmi Violet and the Orient F1 varieties over the period of June.

Whatever the period and given the drying temperature are, the effective diffusivity coefficients averages for the Galmi Violet variety range from $2.25 \times 10^{-11}$ $\pm 2.28 \times 10^{-12}$ to $1.32 \times 10^{-10} \pm 1.17 \times 10^{-11} \mathrm{~m}^{2} \cdot \mathrm{s}^{-1}$ whereas those of the three other varieties evolve from $1.30 \times 10^{-11} \pm 1.24 \times 10^{-13}$ to $9.77 \times 10^{-11} \pm 1.50 \times$ $10^{-13} \mathrm{~m}^{2} \cdot \mathrm{s}^{-1}$.

Furthermore, the average activation energy necessary for the Galmi Violet variety, which ranges from $58.74 \pm 0.11$ to $66.71 \pm 0.12 \mathrm{KJ} \cdot \mathrm{mol}^{-1}$, is superior to that 
of the Safari, Gandiol F1, and Orient F1 varieties. The latter are between $47.63 \pm$ 0.29 and $59.12 \pm 0.13 \mathrm{KJ} \cdot \mathrm{mol}^{-1}$.

The effective diffusivity coefficients and activation energy values are consistent with those of the food products namely okra, green beans, corn, olive leaves.

It is possible to envisage a mixture of the three varieties during the drying whatever the temperature, because their activation energies and their effective diffusivity coefficients are almost identical. In the case of a mixture of the four varieties, the Galmi Violet variety, with the highest effective diffusivity coefficients and activation energy, would be limitative although the different statistical tests do not show any significant difference (except between the Galmi Violet and the Orient F1 varieties).

\section{Conflicts of Interest}

The authors declare no conflicts of interest regarding the publication of this paper.

\section{References}

[1] FAOSTAT (2016) Food and Agriculture Organization Corporate Statistical Database (FAOSTAT). http://www.fao.org/faostat/fr/\#country/195

[2] Albitar, N., Mounir, S., Besombes, C. and Allaf, K. (2011) Improving the Drying of Onion Using the Instant Controlled Pressure Drop Technology. Drying Technology, 29, 993-1001. https://doi.org/10.1080/07373937.2010.507912

[3] CIQUAL (2017) Ciqual Table de Composition Nutritionnelle des Aliments. https://ciqual.anses.fr/

[4] Krokida, M.K., Karathanos, V.T., Maroulis, Z.B. and Marinos-Kouris, D. (2003) Drying Kinetics of Some Vegetables. Journal of Food Engineering, 59, 391-403. https://doi.org/10.1016/S0260-8774(02)00498-3

[5] Babalis, S.J. and Belessiotis, V.G. (2004) Influence of the Drying Conditions on the Drying Constants and Moisture Diffusivity during the Thin-Layer Drying of Figs. Journal of Food Engineering, 65, 449-458. https://doi.org/10.1016/j.jfoodeng.2004.02.005

[6] Bonazzi, C., Dumoulin, E. and Bimbenet, J.J. (2008) Le séchage des produits alimentaires. Industries Alimentaires et Agricoles, 125, 12-22.

[7] Jeantet, R., Croguennec, T., Schuck, P. and Brulé, G. (2008) Sciences des Aliments 1 Stabilisation biologique et physico-chimique. 13-19, 233-244.

[8] Clemente, G., Frías, A., Sanjuan, N., Benedito, J. and Mulet, A. (2011) Influence of Air Velocity in Dehydration of Potato Cubes. III European Drying Conference, Palma de Mallorca, 26-28 October 2011, 26-28.

[9] Doymaz, I. (2010) Evaluation of Mathematical Models for Prediction of Thin-Layer Drying of Banana Slices. International Journal of Food Properties, 13, 486-497. https://doi.org/10.1080/10942910802650424

[10] Brooks, M.S., El-Hana, N.A. and Ghaly, A.E. (2008) Effects of Tomato Geometries and Air Temperature on the Drying Behavior of Plum Tomato. American Journal of Applied Sciences, 5, 1369-1375. https://doi.org/10.3844/ajassp.2008.1369.1375

[11] Madamba, P.S., Driscoll, R.H. and Buckle, K.A. (1996) The Thin-Layer Drying Characteristics of Garlic Slices. Journal of Food Engineering, 29, 75-97. 
https://doi.org/10.1016/0260-8774(95)00062-3

[12] Sarsavadia, P.N., Sawhney, R.L., Pangavhane, D.R. and Singh, S.P. (1999) Drying Behaviour of Brined Onion Slices. Journal of Food Engineering, 40, 219-226. https://doi.org/10.1016/S0260-8774(99)00058-8

[13] Kiranoudis, C.T., Maroulis, Z.B. and Marinos-Kouris, D. (1992) Drying Kinetics of Onion and Green Pepper. Drying Technology, 10, 995-1011. https://doi.org/10.1080/07373939208916492

[14] Mazza, G. and Lemaguer, M. (1980) Dehydration of Onion: Some Theoretical and Practical Considerations. International Journal of Food Science \& Technology, 15, 181-194. https://doi.org/10.1111/j.1365-2621.1980.tb00930.x

[15] Hallouin, I., Mazollier, C. and Ferrera, S. (2014) Fiche culturale: Oignon botte et oignon de conservation. Chambre d'agriculture des Bouches-du-Rhône. Agriculture et Terroir, 1-15.

[16] Programme d'Aménagement et Développement Economique des Niayes (PADEN) (2014) Fiche Technique de bonnes Pratiques de production d'oignon dans les Niayes. MAER, Sénégal. Unite de Coordination du Programme (UCP), 1-6.

[17] Corzo, O., Bracho, N. and Alvarez, C. (2008) Water Effective Diffusion Coefficient of Mango Slices at Different Maturity Stages during Air Drying. Journal of Food Engineering, 87, 479-484. https://doi.org/10.1016/j.jfoodeng.2007.12.025

[18] Doymaz, İ. (2005) Drying Characteristics and Kinetics of Okra. Journal of Food Engineering, 69, 275-279. https://doi.org/10.1016/j.jfoodeng.2004.08.019

[19] Doymaz, I. and Pala, M. (2003) The Thin-Layer Drying Characteristics of Corn. Journal of Food Engineering, 60, 125-130. https://doi.org/10.1016/S0260-8774(03)00025-6

[20] Guillard, V., Broyart, B., Bonazzi, C., Guilbert, S. and Gontard, N. (2003) Modelling of Moisture Transfer in a Composite Food: Dynamic Water Properties in an Intermediate a w Porous Product in Contact with High aw Filling. Chemical Engineering Research and Design, 81, 1090-1098.

[21] Souraki, B.A., Ghaffari, A. and Bayat, Y. (2012) Mathematical Modeling of Moisture and Solute Diffusion in the Cylindrical Green Bean during Osmotic Dehydration in Salt Solution. Food and Bioproducts Processing, 90, 64-71.

https://doi.org/10.1016/j.fbp.2010.11.015

[22] Honoré, O.K., François, Z., Raguilignaba, S., Aboubacar, T. and Hélène, D. (2014) Characterization of Okra Convective Drying, Influence of Maturity. Food and Nutrition Sciences, 5, 590-597. https://doi.org/10.4236/fns.2014.56069

[23] Ndapeu, D., Njeugna, E., Bistac, S.B., Drean, J.Y., Fogue, M. and Foba, J.N. (2013) Experimental Study of the Drying Kinetics of the Coconut Shells (Nucifera) of Cameroon. Materials Sciences and Applications, 4, 822-830.

[24] Nguyen, M.-H. and Price, W.E. (2007) Air-Drying of Banana: Influence of Experimental Parameters, Slab Thickness, Banana Maturity and Harvesting Season. Journal of Food Engineering, 79, 200-207. https://doi.org/10.1016/j.jfoodeng.2006.01.063

[25] Nourhène, B., Mohammed, K. and Nabil, K. (2008) Experimental and Mathematical Investigations of Convective Solar Drying of Four Varieties of Olive Leaves. Food and Bioproducts Processing, 86, 176-184. https://doi.org/10.1016/j.fbp.2007.10.001

[26] Ahouannou, C., Jannot, Y., Lips, B. and Lallemand, A. (2000) Caractérisation et modélisation du séchage de trois produits tropicaux: Manioc, gingembre et gombo. Sciences des Aliments, 20, 413-432. https://doi.org/10.3166/sda.20.413-432 
[27] Benhamou, A., Idlimam, A., Lamharrar, A., Benyoucef, B. and Kouhila, M. (2008) Diffusivité hydrique et cinétique de séchage solaire en convection forcée des feuilles de marjolaine. Revue des Energies Renouvelables, 11, 75-85.

[28] Touati, B. (2008) Etude théorique et expérimentale du séchage solaire des feuilles de la menthe verte (Mentha viridis). Ph.D. Thesis, INSA, Villeurbanne. 